\title{
'Thrown in at the Deep End': The Experience of Graduates of Transnational Western Medical Education Transitioning into Middle Eastern Clinical Practice
}

\author{
Fiza Rashid-Doubell ${ }^{1} \&$ Timothy P Doubell ${ }^{1}$ \\ ${ }^{1}$ RCSI Bahrain, School of Medicine, P O Box 15503, Adliya, Kingdom of Bahrain \\ Correspondence: Fiza Rashid-Doubell, RCSI Bahrain, School of Medicine, PO Box 15503, Adliya, Kingdom of \\ Bahrain.E-mail: frdoubell@rcsi-mub.com; tdoubell@rcsi-mub.com
}

Received: August 19, 2019

Accepted: September 17, 2019

Online Published: September 19, 2019

doi:10.5430/ijhe.v8n6p36

URL: https://doi.org/10.5430/ijhe.v8n6p36

\begin{abstract}
Background: Newly qualified doctors educated in their home country usually go on to work in their first hospital job in same country. These graduates are familiar with the socio-cultural context of clinical setting they work in. But, with many Western universities providing cross-border education to host countries in the Middle East and South East Asia in subjects such as medicine. The experiences of those graduating from transnational medical education and working in local hospitals are absent.

The aim of the study was to explore the early transitional experiences of newly qualified doctors moving from a European branch campus to practice at hospitals affiliated to the medical school situated in a Middle-Eastern country.

Methods: A qualitative study using an interpretive phenomenological approach through interviews to explore experiences of graduates of transnational medical education working in Middle Eastern hospitals.

Results: The main findings can be summarised under the three themes generated: the essentials of practice, routine of practice and realities of practice. The results evidenced the transition as a challenging period for new doctors finding dissonance between the skills taught while in transnational education and the workplace. There were three particular areas of discord for the graduates in clinical practice: working in medical teams with a different arrangement to the one prepared for; adapting to a more patient-centred language and coping with differences in ethical norms, values and practices in the hospital.

Conclusions: The graduates found transitioning from university to full-time clinical practice difficult and were disappointed by their experience not matching their expectations of work. These findings are valuable for transnational medical educators seeking to improve the experience of graduates who are moving from the clear ideals, norms and values of transnational medical education into the complexity of full-time clinical practice.
\end{abstract}

Keywords: transition, transnational, Middle East, medical education, clinical practice

\section{Introduction}

Western medical schools have cornered the market for internationalisation of medical education by setting up off-shore campuses in host countries such as the Middle East and South-East Asia to deliver transnational education. Good examples of successful establishments include the branch campus set up by Royal College of Surgeons in Ireland (RCSI) in Bahrain, Weill Cornell medical college in Qatar and Monash University's institution in Malaysia. However, little is known about the challenges facing these newly qualified Western educated doctors, working locally in strongly hierarchical hospital settings different from the ones they were prepared for at university. One cross border study in the region conducted by Hamdy and colleagues in 2010 examined the challenges for medical schools based in the Gulf Cooperation Council and reported that shortages of faculty and availability of training facilities limited delivery but failed to reveal the challenges for doctors taught in transnational institutions going on to work in Middle-eastern hospitals (Hamdy et al. 2010).

Transitional challenges experienced by newly qualified graduates have been well documented (Brennan et al. 2010; Jones et al. 2016; Lempp et al. 2005b; Prince et al. 2004). The shift from learner to practitioner has been recognised as a major challenge for newly qualified doctors, with burden of workload and new responsibility identified as the 
main work-related problems (Prince et al. 2004; Hurst et al. 2013). To address the mismatch medical educators over the last two decades have redesigned the curriculum moving away from the common place didactic teaching approach more focused on patient centric encounters and student-centred learning getting them ready for practice. Despite the integration of practice ready features built into modern undergraduate curriculums, junior doctors continue to struggle with the challenges of being a doctor. However, those leaving from graduate entry schemes seem better prepared for the workplace (Cave et al. 2009; Lachish et al. 2016; Shacklady et al. 2009; Finucane and O’Dowd 2005).

These type of findings are typical of newly qualified doctors receiving medical training and preparation aligned with a sociocultural environment readiness for practice in their home country. However, the internationalisation of medical education brings with it a different set of challenges for transitioning recipients of transnational education. During this move students educated with one set of professional norms and values originating from the West start clinical work at hospitals with a Middle Eastern set of sociocultural and ethical norms. The impact of this on the junior doctors remains unexplored. The aim of this qualitative study using a phenomenological approach was to explore early transitional experiences of junior doctors who start work at hospitals in a small Middle East country after they have graduated from a cross border branch campus taught using an Irish medical curriculum.

\section{Methods}

Interpretative Phenomenological Analysis (IPA) was chosen as the method of enquiry (Smith et al. 2009). IPA was developed as a research approach in psychology to capture experiences of individuals and has become popular with psychological and health science disciplines (Bäckström and Sundin 2007; Biggerstaff and Thompson 2008), and is growing in its application in educational research (Denovan and Macaskill 2013). In the context of the current project, IPA appears to have a capacity to provide a methodological context in which rich descriptions can be garnered from how individuals making sense of their experiences after key transitions by exploring and analysing their reported experiences. This approach situates participants in their specific event, and explores their experiences of the phenomenon under investigation through face-to-face interviews. This method does not rely upon data saturation. Study protocol was approved by the Institutional Research Ethics Committee.

The Royal College of Surgeons in Ireland (RCSI) is one of five surgical training colleges in the United Kingdom and Ireland primarily providing postgraduate examinations for surgical trainees. RCSI uniquely delivers an undergraduate curriculum at the main campus in Dublin, Ireland and successful transnational medical education across two international campuses (Bahrain and Perdana, Malaysia) to students from over 40 countries. The annual enrolment of students into the first year of the medical programme is between 150 to 170 students. The graduants from RCSI Bahrain make a workplace choice of either working locally as interns for a year at one of the three main local hospitals in Bahrain or moving regionally or internationally depending on their final destination for residency training. The majority of international graduates are provided with an internship opportunity after graduation at either one of the three hospitals affiliated to RCSI Bahrain, the first, a national public hospital the other two associated with the armed forces.

A small purposefully sampled group of graduates were invited to participate in the study. They had recently graduated from an international branch medical school based in the Middle East and were working at one of the three main hospitals in the country. The term "intern" is frequently used in the United States and Australia to describe the first year of clinical training for a newly qualified graduate. For the purposes of this study, we have used this term to describe a first-year doctor who after graduation undertakes a year of hospital practice under supervision, before embarking on residency training. Both researchers were faculty members but had not taught the selected students prior to the commencement of the study. Participants were provided with participant information leaflet containing the aim and objectives of the study, the voluntary nature of participation and the consent process. Following agreement to participate in the study a sample of 5 men and 4 women (a mixture of local (Bahraini) and international interns) were recruited. Those interviewed were a mixture of graduates working at one of the three hospitals and at least one graduate from each hospital was interviewed.

A total of 9 in-depth face-to-face interviews were conducted in a private quiet office space located in the medical campus. They were conducted in English using an interview guide. The interviewer commenced with a verbal confirmation of the voluntary nature of the interview and emphasising the freedom of the participant to withdraw at any time. This was followed by a brief overview of the aim and objectives and an explanation of how the participants' confidentiality would be maintained by the investigators. Once they had agreed to participate they were given a consent form to read and sign.

The interview was initiated with an icebreaker and guided by interview questions developed by one of the authors. 
The interview guide were written to ensure that participants were given an opportunity to provide full, rich accounts of their experiences during the first few weeks of their internship. In addition, the topic guide was flexible enough to permit the interviewer to follow-up and probe interesting areas which emerged during the conversation. The interviewer made notes where necessary. Participants were asked to meet the interviewer at a time which was most convenient to them. A reminder was sent by email the day before the interview detailing the time, venue and name of the interviewer. Interviews lasted between 30 to 90 minutes and there were no repeat interviews. The findings were not reported back to the participants.

All the interviews were audio-recorded. Participants were not identified by name on the audio tape to ensure their anonymity. The digital audio recording was password protected and uploaded on to a professional transcription service site in Europe and transcribed verbatim. Transcribed interviews were not returned to the participants for feedback.

One of the interviewees requested for their interview be removed before the data analysis. This request was honoured. The author read and re-read the eight remaining transcripts several times making personal notes and reflections. Then the transcribed notes along with field notes were subjected to a line-by-line analysis paying close attention to experiential claims, concerns and understandings of the participants. Key words, phrases and or descriptions from the participants were documented, as the author reflexively engaged with the data. Convergence and divergence of data was noted leading to the development of preliminary set of emergent themes. These themes were further interrogated and refined with reference to participants' original words while also including the author's collective interpretations.

\section{Results}

Three main themes generated from data analysis were (i) the essentials of practice, (ii) the routine of practice and (iii) the realities of practice.

The first few months of practice were a challenging time for the interns most felt they "didn't know what to expect or what was expected of them and what they should be doing," (Intern 3).

The first main theme, the essentials of practice encompassed three subthemes, the first one, evidencing the weight of responsibility they began to feel in their roles as doctors. The second subtheme, revealed their disappointment in discovering that a large part of their clinical job centred on completing paperwork. The third subtheme describes how they gained new knowledge, informed existing clinical knowledge and applied it under supervision.

The second main theme focused on the routine of practice and centred on establishing trusting relationships to ensure effective and safe practice, a significant part of clinical work and one which permeated all aspects of the data. The important relationships were between themselves and members of the healthcare team and developing trust between patients and their families.

The third main theme centred on the realities of practice concentrating on the human aspects of caring. This included the discord arising while tussling with appropriate ethical practice. As well having to refine professional language making it more patient-friendly by simplifying terms to improve communication between themselves and their patients.

\subsection{Essentials of Practice}

\subsubsection{Responsibility}

Responsibility was integral to the participants' experience of feeling like a doctor. Some participants described the responsibility for patients a forging feature of care and one that united them with other members of their team. A few participants disclosed before starting work their expectations were high on being given a great deal of responsibility but disappointed once they started work. Several participants found themselves without any responsibility. This was temporary for most and improved after a few weeks at work as the senior doctors began to trust in their abilities to work autonomously.

Intern 8 - "So I thought there are more responsibilities on an intern than what I expected so my expectation changed but now I think I should go back to the previous expectations... Which was like interns don't do much they are mostly students but can write medical papers."

Intern 5 - "The first few weeks we went with very high expectations that we will be asked to do a lot and that we will be given some responsibilities. But that did not happen ...It was kind of shocking for us because we were even like less involved than being a student."

Many of the interns explained that both the level of responsibility assigned and their involvement in patient-care 
fluctuated and was determined by two factors, either on the clinical situation they found themselves in, or on the senior doctor's level of trust in them.

Intern 5 - "By the end of those 2 weeks things started to change, like some of the seniors started to have trust in us, that we are able to do things, we are trained to like read labs."

Intern 2 - "Definitely I feel like I have a lot more responsibility... I feel more important and that I'm actually part of a real team. '

Responsibility could take many guises with one participant describing how they felt theirs was more of an internalised form and one which they considered an essential part of their role.

Intern 3 - "What's different is that I have responsibilities now. As a student I could theoretically not be there and no one will be negatively affected, as an intern you have to be there. That's fine because we all want to be there for the benefit of the patient."

An unusual factor affecting the amount of responsibility given to participants was the hospital's annual intake of interns. Participants working at this hospital commented that the larger than normal influx resulted in them working in wards with up to 8 other interns and some of participants assigned only two to three patients to care for, limiting their clinical exposure.

Intern 5- "You will end up having two patients or three as maximum and that was one of the things that like caused us having nothing to do. It's like kind of interns overload."

\subsubsection{Administrative Burden}

Most of the participants described the newly acquired administrative load at the start of the internship as an unwelcome surprise. Although both males and females were amazed. The male participants were especially taken back with one describing it as doing "secretary work". Nearly all of them regarded the paperwork as a default option to occupy their time.

Intern 2 - "In med school I felt we focused more on clinical knowledge. But now I feel most of the focus is on secretary work... I'll go and clerk all the patients, write all the notes, do all their requests."

The amount of clerical work done by interns were again determined by the senior doctors and the size of the healthcare team. When interns worked in smaller groups, the dynamics shifted with participants finding themselves experiencing a change in role relative to their status from intern to junior doctor, a position which afforded greater responsibility. This 'promotion' was made by the senior doctor and usually happened during staff shortages. On these occasions, the onus was for the intern to do less administrative work and complete more hands-on patient-centred activities to keep pace with patient load.

Intern 3 - "I would be typing up notes, because I'm responsible for making all the requests and just typing up all the notes, discharge requests reports all that sort of stuff."

Intern 4 - "It's not hard work it's a lot of work, basically. We need to do for example, we usually clerk the patients before the rounds, before rounds start."

Intern 8 - "We're mostly just doing the secretary work...Well mainly discharge summaries. At the start even notes, they were not letting us write notes... Each group different dynamics, like in G.I. there was chief, senior and junior. In Nephrology, there was only senior and me. [They would say to me], okay now, after you've examined and taken the history what do you think is wrong with this patient? How would you manage this patient?"

\subsubsection{Supervised Support}

During the first months of practice the interns needed support to navigate through the complex clinical situations they found themselves in. Support came in two forms either informal with family members who were medical practitioners providing help to some participants. While a few others were helped by senior alumni from the same medical school.

Intern 1 - I think I am really lucky because ... my sister is a doctor as well and she has been there for three years now and she has helped me a lot especially in the first two days. Because everyone was telling me so ok go do the admissions, go do the discharge, check the referrals, go do this and do that and I had no idea what I was doing... So the good thing is that we do have other RCSI [Bahrain] alumni as well so they have been really helpful as well. They taught me how do cannulas, how to insert a Foley's catheter, you name it."

Formal support came from senior house officers (SHOs) and residents as well as the nurses. One participant 
described how the SHO were really useful in helping them manage the day-to-day logistics of working in the hospital. The interns also approached nurses to help them when the SHOs weren't around.

Intern 2 - "The senior house officers who taught me how to use the computer, how to do the notes, how to do the requests and everything and when the senior house officers weren't around the nurses were a huge help. They pretty much told me what to do in the first month."

Intern 8 - "Thankfully for the first two weeks I had a new resident with me and she was really helpful. She taught me a lot, how to use the system, how to use the electronic healthcare system-everything."

Healthcare professionals were not the only people providing support to junior doctors in the hospital. One participant working at one of the hospitals was assigned medical administrative staff to provide them with assistance, this was welcomed by the intern.

Intern 1 - "Two secretaries, they are there just for the interns to support the interns...they ask like are there any problems, are you facing any issues with any of the nurses, or doctors and things like that. Just to be safe, that's mainly it if we need any support or someone to talk to."

\section{Building knowledge and skills}

Interns described how learning had become more a challenge as it changed from a structured formalised to an unstructured more hands-on approach. This change of approach and lack of structure was mentioned by one of the participants who expressed surprise the absence of organised teaching.

Intern 6 - "He [the consultant] goes with us and we discuss guidelines, the common guidelines, what they are used for ......but still yet for us there is no structured teachings there."

The data evidenced that responsibility of learning shifted away from teacher driven towards participant driven with the intention of changing to an autonomous learners and acquiring knowledge while they practiced medicine. One participant described the struggle in finding the time to learn. They also became acutely aware that a shift had occurred in what they were learning, moving away from acquisition of theoretical knowledge towards hands-on patient-centred skills, especially during rotations like surgery. The studying was unstructured causing some participants discomfort for being solely responsible for their learning.

Intern 2 - “... it's more my responsibility to learn. They don't have responsibility to teach me... I don't have time to properly learn but the learning is now more it's more focused on hands-on practical stuff than knowledge. The knowledge is totally up to me. Knowledge is basically when I have the time at hospital I'll sit when I'm done with work, I'll sit and read."

Intern 5 - "What we are doing is just self-study, whatever cases we see we have to go and read about them and so whatever questions we have, we have to do it ourselves."

Intern 8 - "I found that you have to teach yourself everything, nobody will teach you...your team doesn't actually take time and say, come here, we want to show you this case, nobody does that, you come and find out yourself."

Another feature of the learning acquisition in the clinical setting was that most of it was done through observation. Several participants valued this approach to learning. Watching other members of the healthcare team improved the interns understanding of work-based practice.

Intern 3 - "I learned by watching and then you know by just doing things and figuring things out and you know over the past few week... a lot of that [learning] is in-between lately. I haven't found as much time as I would have liked but you make do...[learning] happens all the time, during the wards, wherever there's procedures, you sometimes get handed, they tell you, do this procedure."

Intern 4 - "You do everything by watching at the start...you just watch other doctors make the mistakes. You know what I mean and then you do it...I don't learn from people, telling me this is the information. No learn by like watching doctors, how to manage patient, how he is talking to the patient."

\subsection{The routine of practice}

The theme of routine of practice could be subdivided into three further components. The first two described the importance of building relationships with their healthcare teams and their patients and its impact on their work. The third centred on the interns' experience of negotiating the hospital systems which was essential element in accomplishing routine care. 


\subsubsection{Building relationships with the team}

The data evidenced that successful day-to-day practice was established on developing trusting relationships. Building trust for the participants was a core consideration when attempting to form a rapport with others in the healthcare team. Trust between themselves and their patients formed the cornerstone of good patient care, this bond also extended to close family members. Building these trusting links with the team members inadvertently led to improved navigation of the hospital systems. One participant in particular pinpointed two factors which impeded the formation of a strong bond with senior doctors. First the confrontational nature of some consultants with one person describing it as "going to war." Second, the difficulty in reaching senior doctors for consultations (Intern 7). This resourceful intern solved this particular problem by over-preparing themselves to be ready to answer any and all questions about the patient when the senior doctors eventually arrived at the bed-side (Intern 7).

Generally the healthcare team consisted of a mixture of doctors including a consultant, senior registrars, registrars and house officers plus the intern(s). The exact number in the team depended on the clinical context. For example, the Nephrology rotation at one hospital consisted of only one consultant and one intern, but the Surgery rotation at another hospital had up to six members in the team.

The size of the healthcare team was an important determinant for the successful integration of interns into the team. This was exemplified by participants' experience of finding communication generally easier in smaller teams and the hierarchy less pronounced. But those who unfortunately found themselves in larger teams described the hindrance to their day-to-day performance based on hierarchical particularities frequently found both communication and effective practice impeded. One male participant working on an Obstetrics and Gynaecology rotation recounted how even though he was in a smaller team the hierarchical command structure was still present.

Intern 2- "During the rounds I address the most senior person if I have any questions or any concerns...but outside of the rounds...I usually address, it's like a chain of command I go through the SHO first and if they don't know then we can go one step higher... [the consultant] they're always happy to answer, always happy to help it's just the consultant's harder to get hold of they are usually busy with other things."

Intern 3 - "There's usually an intern (me) and a SHO who are there most of the time... I haven't myself, I haven't had an issue. I suppose military style you follow chain of command and the SHO is the one most available to you anyway."

Intern 4 - "The most likely you can ask them whatever you like and they will help you out. There is no hierarchy if you know what I mean you don 't have to go to speak to the registrar or to the consultant."

Interns obviously considered other doctors as part of the healthcare team but they had mixed feelings towards nurses being part of the group. The data showed that one or two interns did not consider nurses as team members. A small number of participants reticently included nursing staff as team affiliates by using the phrase "even the nurses". The data also evidenced that the remainder valued the presence of nurses as important facilitators to performing their day-to-day tasks.

Intern 2 - "When the senior house officers weren't around the nurses were a huge help...it's mainly the nurses who help. Anything, ANYTHING that I want or need to know the nurses are there to help."

Intern 3 - "No... [I ask the] nearest person around me even nurses; they've been a great help. They tend to know the system sometimes better than the doctors."

Intern 7 - "So I think the hassle is only in trying to ask certain people to like get what you want to do and get it done but I think, I don't know, I wouldn't say like I have experienced anything. The doctors are nice and understanding, even the nurses."

3.2.2 Building relationships with patients and family members

Patient care involved two clear tasks for the interns during their day-to-day clinical routine. First, they had to ensure that the patient's paperwork was current, present and correct. Second and more importantly for the participants was developing a good relationship with the patient and in some cases with the family members. Most remarked the importance of this relationship helping them to consolidate their professional doctor identity and how it contributed towards building their self-confidence. Moreover, this investment rewarded the patients by them feeling more trusting towards the junior doctors.

However, the data revealed three circumstances where interns struggled to build these essential trusting bonds with their patients. The first, was when the interns discovered that even though the routine administrative work for their patients was a necessary part of their job it did not help towards establishing a connection with the patients. 
Intern 2- "A typical day maybe I have to be there rounds, morning rounds start at seven in the morning so I have to be there at 6.30. I have to prepare, I have to review all the patients, if there's any new admissions, any elective admissions. Find out if their labs are out yet and prepare all their labs. If there any out yet, if there's any imaging studies that were done I have to know about those and I have to prepare that and know about all the patients and then when we start morning rounds I am supposed to take notes on...you know how the patients are and if there's any plans for the patients and if the doctor has any questions about any labs done I have to be able to answer those. So I have to basically stay on top ... you know what's been going on with the patients."

Intern 6- "I deal with stuff like, for example, like administrative, like the admission papers, following up patients once the consultant...after consultants...before they come, like dealing with any changes that happens with the patient."

The second situation, where the interns struggled to connect with their patients, was when their routine changed and they found themselves on-call. During these periods their patient load rose and some of them found it difficult and challenging to properly communicate with their patients.

Intern 2 - "I find it more challenging from like a work hours perspective it's a lot longer work hours, we have to do on-calls now, which can be very tiring especially when your sleep gets interrupted and you have to get up constantly."

The third situation where the participants struggled to form trusting relationships was when their patients were in the intensive care this severely impeded communication. Under these circumstances, the intensive care unit did not facilitate patient interaction as one participant described below.

Intern 7 - "You need [patient] interaction. How can I with a ventilated patient, like in a comatosed patient, how can I do an interaction? I need to be interactive with the patient."

The data evidenced that hands-on care of the patients allowed the participants to form strong and connected relationships with them. One participant described that since starting work they had begun to pay close attention to their patients, particularly the older patients on the medical wards. They felt more concerned about them. This participant realised there were two components of patient care, a more physical responsibility to provide care but also an emotional element with development of increased feelings towards the patient, they described this as "being human". Learning how to build these connected relationships with patients required watching, learning and emulating the senior team members' behaviour and patient-centred language used around the patients.

Intern 1 - "I do feel really concerned about them [the patients]. I don't know I guess it's part of being human. So not just the work responsibility it's the emotionally how you feel as well."

Intern 6 - "We learn from our seniors how to react, to deal with patients. As students you are usually an observer, right, but then now that you participate more you know how to deal with patients, you know how to professionally act in the presence of patients, ask the proper questions. So if you ask the proper questions and you wear the proper uniform then people will assume that you're a doctor."

One participant revealed how the physical act of caring for patients rather than just writing notes on them made them feel more responsible and appreciative towards them.

Intern 8 - "Well if they [senior doctors] let you care for the patient you feel it but... if you just write notes I don't feel the responsibility towards the patient but if they let me, okay, every day you go do the history and examine the patient and do everything, I will really feel obligated towards the patient,"

This participant also went on to provide a detailed description of the care they provided for an older woman in the Nephrology unit who was dying. The intern had arrived into the hospital earlier than the rest of their team. They were met by the woman's daughter who could see her mother was deteriorating and requested a detailed medical update from the intern. The intern didn't feel they had the authority to provide this information to the daughter and so both waited for other team members to arrive into work. The intern explained that she felt the other team members were detached from caring for this patient. She discerned this behaviour from actions of senior doctor such as entering the room to complete a diagnostic request and leaving abruptly without speaking to the patient.

The importance of showing care for patients was extended by the interns to include the patients' family. The practice of care was enhanced on occasion when there was an existing familiarity between the intern and the family member. One example would be neighbours from the same community who they had grown up with. Another would be attending to patients who had worked at the institution they had studied at. Moreover, some of the participants established a sense of closeness with the patient by being the first person to deal with them when they arrived into 
hospital. The continuity of care brought them into close proximity with the patient's family members who were always nearby.

Intern 6 - "Personally, yeh. I've grown up with them, and I know them and they just happen to the mother had knee pain or something and she was at the hospital. And basically I made sure I was there for the patient, like made sure that her medications were there and everything and they were very happy not just cos I knew them but because I basically took care of the patient not, nothing personal or anything."

Intern 8 - "Maybe because from the emergency they saw me and then they were like the wife used to work in my university so she was like 'You were an RCSI student?' and I was 'Yes...For two weeks yeah because he was admitted ... in the emergency I was the one who did the admission papers so they knew me and then they were like ... he and his wife... when they need anything they prefer to talk to me not the others...So like I was let's say the connection between this patient and his family and even the whole team."

The paediatrics rotation was a case in point where part of establishing strong bonds of care for young patients included listening to their parents. The parents vented a range of emotions from frustration to anger as well as being tired and irritated. The intern considered reassuring and making the parents feel appreciated as an essential part of this rotation.

Intern 7 - "I make sure that I be nice to the parents, like you establish a good relationship with the parents first because I'm mostly dealing with them... they will vent out on you, it's not your fault, however, you just like want to suck their anger (laughs) and at least just make them feel better. You know they feel better. They feel appreciated."

\subsubsection{Negotiating hospital systems}

Some of the participants expressed how they felt wholly unprepared to negotiate hospitals systems in the early weeks of clinical practice. Obviously, being new to the workspace played large part in the disorientation but also how they went about familiarising themselves with working practices of the hospital was another problem. One solution to acquainting themselves with necessary work practices was to ask more than one team member to gain reaffirmation of the protocol. One intern described the experience as being "thrown in the deep end" as they learned how to navigate the hospital. Other interns described how the senior doctors were happy to provide helpful advice over the phone even after they had left the hospital. Even the consultant were happy to share their contact details in order to be updated with the patient's status.

Intern 3 - "But you know I suppose it's the same with all new jobs really, yes you get thrown into the deep end but you sometimes but you know you pick things up like it wasn't as bad as I expected it to be."

Intern 4 - "We go to the registrars they gave us there personal numbers to contact them... Also when the consultant comes, he gave his personal number so that's I just keep him up-to-date on whatever"

Intern 7 - "Maybe just like sometimes you are new to the system, you don't know what to do or if you want to get something done sometimes you have to ask multiple people to make sure that you get it correctly done."

One or two of the hospitals did offer participants an orientation before they started work. Those who attended described the inductions as minimal, disorganised and lacking in information about schedules and protocols, instead housekeeping concerns such registering for sick leave were shared.

Intern 3 - "The first three days were unofficial orientation days basically. During the orientation what surprised me was giving specific permission about er...regarding sick days. Sick leave and us [the interns] having to have sick leave verified by the [senior] doctor."

Some participants struggled with completing a small but significant number of clinical tasks unique to the hospital system. How to write discharge papers for patients was one example given by a participant another was the process of issuing death certificates. The uncertainty in knowing how to complete these tasks unsettled this participant.

Intern 6 - "Like how to properly do an admission that's based on the Bahraini system and also discharge papers and a death certificate"

\subsection{The Realities of Practice}

The interns described that in practice the reality of their work was dominated by three subthemes: developing their doctor identity, ethical practice, shaping attitudes and language.

\section{Developing their doctor identity}

The first few months of practice bought with it an uncertainty in their doctor identity for some interns. One of them 
described this incongruity as occupying "a space in-between a student and a doctor". Another explained how they sought self-validation of their identity through their achievement of graduating as a doctor.

Intern 5 - "In between - between student and doctor...now that you participate more you know how to deal with patients, you know how to professionally act in the presence of patients, ask the proper questions. So if you ask the proper questions and you wear the proper uniform then people will assume that you're a doctor."

Intern 4 - "I still got the fear, like it's there but usually like I had the feeling after graduation that ok now I'm a doctor."

Others considered this period of identity development as a more positive experience. Feeling like a doctor was determined by two things. The opportunities afforded to practice their patient-centred skills autonomously and by having their work validated by other doctors. A good example of the former was given by a participant who described being given sole responsibility for caring and managing patients, taking full histories and completing physical examinations. A second participant explained the importance of recognition in doing a good job from senior doctors contributing greatly towards feeling like a doctor.

Intern 6 - If I am given the responsibility of seeing the patient alone, taking the full history, then doing the proper physical examination and putting a plan of management for the patient then I feel generally that I am a doctor."

Intern 7 - "When you discover that whatever you have written or the feedback like [the senior doctor] will tell you 'Oh doctor your history was really excellent' or 'your examination was correct' and you feel that okay you have been in a difficult situation but you have like managed too and hearing a good feedback is always nice."

Patients also contributed significantly towards the formation of identity. Both directly by being called "doctor" by patients when they addressed them and indirectly through the act of caring for patients making them feel like a "doctor".

Intern 5 - "It's just like the way you are called [doctor] by the patients and the way we are called [doctor] by our family and the other doctors."

Intern 6- "If I am given the responsibility of seeing the patient alone, taking the full history, then doing the proper physical examination and putting a plan of management for the patient then I feel generally that I am a doctor."

\subsubsection{Ethical practice}

Ethical behaviour was fundamental to intern's clinical practice. This was an area where the black and white of theory taught and demonstrated at university conflicted with ethical norms and values in the work place. Several participants described their struggle between taught ethical practice and the practiced behaviour. One good example of this type of conflict was reported by one participant working on a paediatric ward on the arrival of new-born orphan. The child was a ward of the court as it had been born out of wedlock. The absence of parents bought a lot of enquiries from other visitors as to the whereabouts of the baby's mother. The intern knew it was wrong to divulge patient information and responded with vague answers attempting to close the discussion with strangers. However, she was shocked to hear the nurse detailing the orphan's circumstances to a visitor. In the following weeks, the story about the orphan spread and more people came to visit the child. This situation was difficult for the intern to navigate knowing that even though she was not giving out information about the patient, others were going against what they had been taught.

Intern 5 - "They started to ask where is his [the orphan's] mother, why she is not here, where is his father. I tried to give him very vague answers and to stop the discussion and I stopped it. I left their room to just not get any more questions and when I get back I was shocked that the nurse told them most of the story... so actually there was people wasn't were going out and telling his story and other people were coming to see him. It was a really bad thing like."

A second example from a different intern, described concerns over the ethical practice of senior colleagues whilst working in a health centre. In the mind of the junior doctor good ethical practice taught at university was breached on a number of occasions at the centre. It was rationalised to "differences in culture" since the doctors working there were from a number of countries. Most had trained abroad and therefore it was difficult for health authorities to ensure that ethical guidelines were adhered.

Intern 6 - "Like sometimes like what we've been taught, especially when it comes to ethics, the ethical part of it, if it's applied better, especially in the healthcare centre it comes ... ethics are breached a lot in a healthcare centre." 


\subsubsection{Shaping attitudes and language}

The participants described a variable experience in the attitude of others towards them as they performed their roles and how it impacted on them settling into work-based practice. A few explained that a lot more was expected from them now they had graduated than when they were students. Another participant explained for them it had not been a big step from student to junior practioner fuelled in part by expectations of other doctors in the team.

Intern 2 - "Yeah, definitely I feel like I have a lot more responsibility...I feel more important than, and that I'm actually part of a real team."

Intern 3 - "Not a big leap... and what's expected of you, really"

A different intern explained how early in clinical practice, their hospital became saturated with newly qualified doctors. This caused consternation and led to feelings of being "invisible." The overload resulted in other health care professionals ignoring them and their status. One consequence of this invisibility was the participants omitting the term 'intern' during conversations with other healthcare workers and instead qualifying their status by prefixing with details of their superior before the request, e.g. consultant $\mathrm{X}$ want results or information on patient $\mathrm{Y}$.

Intern 8 - There's more interns... They're invisible...No, it's just the way they treat you, like okay, like let's say I've called a senior for consultation, once you say you're an intern...they would say 'No, no I don't understand, can you let the senior talk to me', 'What?' and then the senior takes the phone and just says the same thing and they suddenly understand everything. So now I have stopped saying I am an intern and I just say my name and I am under this doctor and I'm calling for this."

Many of the participants interviewed observed differences between themselves as graduates of an international medical school and others from local, regional, and Asian medical schools. They described the variances in their preparation for practice against the other graduates as noticeable. This discrepancy was also noticed by senior doctors. For some participants this superiority in clinical work was like wearing a badge of honour as graduates from an international programmes afforded them on occasion better treatment from the consultants. The difference between them in readiness for work was mentioned by another participant who encountered the other interns on a rotation looking lost and realising that they did need a lot more help to settle into clinical practice.

Intern 5 - "I would say he [senior doctor] plays a big role. I can say this after seeing interns from very different universities. So in [our hospital] it's different than other hospitals that people from different universities come to join the internship programme and that becomes very obvious, like RCSI students are really ready to take the role as interns and even doctors know that very well"

Intern 6 - "We know everything - the system - but those from outside, from Egypt or wherever, they are lost and they need our help sometimes. Most of the time actually."

One factor which determined whether interns were satisfied with the effectiveness of their clinical work was their ability to communicate clearly with patients. They noticed early on in practice the way they spoke to them needed to change, using more patient-friendly language helped improve their rapport with the patient. Most of the participants learned this modification in speech through observing other doctors and imitating the language used by them during consultations.

Intern 4 - "No learn by like watching doctors, how to manage patient, how he is talking to the patient, the way he's --- the patient."

Intern 2 - "Most of the questions they've asked me are questions that previous patients have asked the doctors so I've picked upon that and I was able to answer."

In summary, the findings showed that in the first few weeks of practice the interns struggled with a number of transitioning factors. These included trying to manage the administration load, building trusting relationships with patients and team members and building a doctor identity. The transition from student to junior doctor was made harder for graduates of a Western medicine programme who felt socially and culturally unprepared for practice in a Middle Eastern hospital. The presence of hierarchical medical teams, the need for including family when building rapport with patients and managing ethical conflicts on their own presented them with a challenging work environment.

\section{Discussion}

The in-depth exploration of experiences during transition of graduates of a transnational education into clinical practice at hospitals in the Middle East reveals both common and distinctive challenges rooted in adjustments in the 
sociocultural context associated with the new workplace. The general challenges described by graduates associated with experiences of their first time working in the hospital included feeling lost, pressured or even overwhelmed and typically being out of their depth most of the time. Experiencing this type of stress associated feelings during the first year of practice are not unusual (Cameron et al. 2014; Hurst et al. 2013; Illing et al. 2008).

One unanticipated consequence in the job of being a doctor was spending a lot of time keeping abreast of patients' paperwork. Administrative work formed a major part of their routine work and often ascribed as a default option to occupy their time (Nash et al. 2016). There were two main determinants for assigning administrative work. The clinical situation was one with those working in a busy clinical environment with many team members heavily burdened with administrative tasks. The senior doctor was the other, they essentially controlled the overall quality of the interns' experience by having the power to assign them more patient-centred tasks reducing the amount of paperwork.

One outcome of working at a hospital in a small country was the probability that the transnational student may be acquainted with the senior doctor. This bought with it both reward and penalties. The newly qualified doctors' experience was boosted when consultants acknowledged the quality of the education received by the transnational graduates and afforded them preferential treatment. On the other hand, their experience was hindered when consultants became confrontational or difficult to contact for instructions, bringing the new practioners misery. This inconsistency in professional behaviour of the senior practioners was an ongoing concern and one which they had not been prepared for.

Responsibility towards patients was integral in fulfilling the role of a doctor (Illing et al., 2008). It came either in the form of developing internal feelings of responsibility towards patients or as an externalised weight of responsibility shared between the team for patients. The expectation of being given responsibility was high before starting work but in reality it either didn't materialise or they were given a small amount. It was not unusual for junior doctors to have expectations of being given a lot more responsibility before they started work and then being disappointed when they started work (Costello et al. 2010). Luckily, this changed quickly once senior doctors started trusting their abilities affording them more responsibility and certain amount of autonomy. Both autonomy and responsibility improved feelings of job satisfaction (Nash et al. 2016). But, too much responsibility in the first year can be detrimental leading to problems with managing workload (Illing et al. 2008; Prince et al. 2004).

Working in the hospital for the first time meant graduates encountered complex clinical situations for the first time and in order to navigate them safely they needed both advice and support. Ensuring safe practice by feeling supported was provided by team members as well as by alumni or family members who worked in the same hospital. The importance of creating a supportive learning environment for trainee doctors has been recognised as a factor contributing to good-patient care (Thomson et al. 2014). Recognised challenges to learning in a busy hospital environment include lack of good supervision (De Lasson et al. 2016; Goodyear 2014), less structured, formalised teaching opportunities and more patient-centred autonomous learning (O'Brien and Poncelet 2010). The study revealed interns struggled with how, what and when they learned and certain clinical situations impeded their learning. A good example of this was when the ward was flooded with new interns and there were not enough patients to go around. Doctors were allocated one or two patients which reduced their learning opportunities.

The graduates faced a frequently described transitional problem of negotiating the new clinical environment as practioners. One way of resolving this would be to provide them with an adequate and timely induction which included details of their role and responsibilities (Miles et al. 2015; Illing et al. 2008; Brennan et al. 2010). But this study showed that each hospital had its own set of clinicocultural idiosyncrasies making a harmonious transition difficult. Junior doctors need context, guidance and legitimacy during the process of transition to help them settle quickly into the workplace (Teunissen and Westerman 2011). Graduates reported that poor orientations prior to starting work left them with a sense of uncertainty over their role and responsibilities. Thankfully, this feeling of uncertainty is temporary with many new doctors adjusting and adapting to their new environment by the end of the first year of practice (Brennan et al. 2010).

One distinctive challenge of a transnational programme delivering clinical teaching in English was that in hospitals there would be multicultural patients speaking a number of different languages. Patient-centred communication presented a significant challenge for junior doctors and affected communication with patients. Acquiring better patient-centred language for their own consultations was done by watching senior clinicians. Opportunities to observe senior staff has been described as a useful way of learning in clinical situations for junior staff (Lempp et al. 2005a).

Another unique challenge bought about by having a transnational medical education using a Western model of 
work-based practice with multidisciplinary teams and an emphasis on the importance of group-decision. In reality, the newly qualified doctors described the hospital specialties as having the medical teams arranged hierarchically and lacking an interdisciplinary integrated approach to care. The junior doctor's absence in the decision-making process resulted in them feeling that their knowledge and skills were not valued by other members of the team. This working arrangement also impeded the formation of trusting bonds between the team members and the new doctors. The easiest healthcare professionals to build relationships with were the nurses, they welcomed an extra pair of hands and were happy to help the interns when they needed it. Nurses played a significant part in the successful integration of junior doctors helping them feel part of the team (Lempp et al. 2005b). Building trusting relationship for interns was an important step towards working more effectively and led to improved patient care.

Having a transnational education bought another challenge for the junior doctors when they moved into the Middle Eastern workplace. Differences in ethical norms and values between the newly qualified doctors and local and regional clinical staff were obvious, affecting their moral and left them feeling helpless. During such encounters interns felt powerless to take action. Others who experienced similar situations appropriated a more pragmatic approach and attributed the mismatch to sociocultural differences. Ethical discrepancies are common in the professional lives of all healthcare workers (Roberts et al. 2004). But new doctors need a significant amount of self-confidence to challenge those responsible for breaching hospital practice (Edwards et al. 2013).

One of the most important relationships for the new doctor was the one between themselves and the patient. The building of trusting relationships with their patients and their families was an essential part of being a doctor. The importance of good patient-care through development of strong human relations was a major transitioning feature indicating the shift from medical student to junior doctor (Jones et al. 2016). However, there were several occasions which deterred this bonding forming process. The first, when there was too much administrative work. Administrative tasks such as completing paperwork are considered an unnecessary part of a new doctor's job and identified as a challenge for them early on in practice (Calman and Donaldson 1991; Roche et al. 1997). The second, when interns were short of time especially during on-call. The third situation when establishing a rapport was difficult was when the patient was in the intensive care unit.

The trainee intern year is seen as an important transition during which they move into a professional role leading to the formation of a professional identity (Wilkinson and Harris 2002). This close relationship between professional identity and performance has been recognised as a prerequisite for membership to the medical community (De Lasson et al. 2016). The data evidenced that this was indeed the case and that a key component of the identity and feeling like a doctor came from the responsibility for, and caring of patients (Lefroy et al. 2017). Hands-on care consolidated the trusting relationships built with patients and increased the graduate's self-confidence in themselves.

\section{Acknowledgement}

This work was supported by an internal RCSI Bahrain grant number BR00052.

\section{References}

Biggerstaff D \& Thompson AR (2008). Interpretative phenomenological analysis (IPA), A qualitative methodology of choice in healthcare research. Qualitative Research in Psychology, 5(3), 214-224 https://doi.org/10.1080/14780880802314304

Brennan N, Corrigan O, Allard J, Archer J, Barnes R, Bleakley A, Collett T, Bere D \& Regan S (2010). The transition from medical student to junior doctor, today's experiences of Tomorrow's Doctors. Medical education, 44(5), 449-458https://doi.org/10.1111/j.1365-2923.2009.03604.x

Bäckström B \& Sundin K (2007). The meaning of being a middle - aged close relative of a person who has suffered a stroke, 1 month after discharge from a rehabilitation clinic. Nursing Inquiry, 14(3), 243-254https://doi.org/10.1111/j.1440-1800.2007.00373.x

Calman K \& Donaldson M (1991). The pre - registration house officer year, a critical incident study. Medical education, 25(1), 51-59https://doi.org/10.1111/j.1365-2923.1991.tb00026.x

Cameron A, Millar J, Szmidt N, Hanlon K, Cleland J (2014) Can new doctors be prepared for practice? A review. The clinical teacher, 11(3), 188-192https://doi.org/10.1111/tct.12127

Cave J, Woolf K, Jones A \& Dacre J (2009). Easing the transition from student to doctor, how can medical schools help prepare their graduates for starting work? Medical teacher, 31(5), 403-408https://doi.org/10.1080/01421590802348127

Costello J, Livett M, Stride P, West M, Premaratne M \& Thacker D (2010). The seamless transition from student to 
intern, from theory to practice. Internal medicine journal, 40(10), 728-731https://doi.org/10.1111/j.1445-5994.2010.02272.x

De Lasson L, Just E, Stegeager N \& Malling B (2016). Professional identity formation in the transition from medical school to working life, a qualitative study of group-coaching courses for junior doctors. BMC medical education, 16(1), 165https://doi.org/10.1186/s12909-016-0684-3

Denovan A \& Macaskill A (2013). An interpretative phenomenological analysis of stress and coping in first year undergraduates. British Educational Research Journal, 39(6), 1002-1024https://doi.org/10.1002/berj.3019

Edwards M, Kelly T, Gainsborough N \& Halligan A (2013). Evolving doctors from medical students. Journal of the Royal Society of Medicine, 106(9), 347-350https://doi.org/10.1177/0141076813484461

Finucane P \& O'Dowd T (2005). Working and training as an intern, a national survey of Irish interns. Medical teacher, 27(2), 107-113https://doi.org/10.1080/01421590400029665

Goodyear HM (2014). First year doctors experience of work related wellbeing and implications for educational provision. International journal of medical education, 5, 103https://doi.org/10.5116/ijme.5380.6ef1

Hamdy H, Telmesani A, Wardy NA, Abdel-Khalek N, Carruthers G, Hassan F, Kassab S, Abu-Hijleh M, Al-Roomi K \& O'Malley K (2010). Undergraduate medical education in the Gulf Cooperation Council, A multi-countries study (Part 2). Medical teacher, 32(4), 290-295https://doi.org/10.3109/01421591003673730

Hurst C, Kahan D, Ruetalo M \& Edwards S (2013). A year in transition, a qualitative study examining the trajectory of first year residents' well-being. BMC medical education, 13(1), 96https://doi.org/10.1186/1472-6920-13-96

Illing J, Morrow G, Kergon C, Burford B, Spencer J, Peile E, Davies C, Baldauf B, Allen M \& Johnson N (2008). How prepared are medical graduates to begin practice. A comparison of three diverse UK medical schools

Jones OM, Okeke C, Bullock A, Wells SE \& Monrouxe LV (2016). 'He's going to be a doctor in August', a narrative interview study of medical students' and their educators' experiences of aligned and misaligned assistantships. BMJ open, 6(6), e011817https://doi.org/10.1136/bmjopen-2016-011817

Lachish S, Goldacre MJ \& Lambert T (2016). Self-reported preparedness for clinical work has increased among recent cohorts of UK-trained first-year doctors. Postgraduate medical journal, 92(1090), 460-465https://doi.org/10.1136/postgradmedj-2015-133858

Lefroy J, Yardley S, Kinston R, Gay S, McBain S \& McKinley R (2017). Qualitative research using realist evaluation to explain preparedness for doctors' memorable 'firsts'. Medical educationhttps://doi.org/10.1111/medu.13370

Lempp H, Cochrane M \& Rees J (2005a). A qualitative study of the perceptions and experiences of Pre-Registration House Officers on teamwork and support. BMC medical education, 5(1), 10https://doi.org/10.1186/1472-6920-5-10

Lempp H, Seabrook M, Cochrane M, Rees J (2005b) The transition from medical student to doctor, perceptions of final year students and preregistration house officers related to expected learning outcomes. International journal of clinical practice 59 (3),324-329https://doi.org/10.1111/j.1742-1241.2005.00438.x

Miles S, Kellett J, Leinster SJ (2015) Foundation doctors' induction experiences. BMC medical education 15 (1),118https://doi.org/10.1186/s12909-015-0395-1

Nash L, Karageorge A, Llewellyn A, Sandhu H, Edwards J, Kelly B, Burke D, Maddocks C, Reynolds K (2016) Accentuate the positives, but don't necessarily eliminate the negatives, a cross-sectional survey of junior doctor psychiatry terms. MedEdPublish 5https://doi.org/10.15694/mep.2016.000110

O'Brien BC, Poncelet AN (2010) Transition to clerkship courses, preparing students to enter the workplace. Academic Medicine 85 (12),1862-1869https://doi.org/10.1097/ACM.0b013e3181fa2353

Prince K, Van de Wiel M, Van der Vleuten C, Boshuizen H, Scherpbier A (2004) Junior doctors' opinions about the transition from medical school to clinical practice, a change of environment. EDUCATION FOR HEALTH-ABINGDON-CARFAX 17,323-331https://doi.org/10.1080/13576280400002510

Roberts LW, Hammond KAG, Geppert CM, Warner TD (2004) The positive role of professionalism and ethics training in medical education, a comparison of medical student and resident perspectives. Academic Psychiatry 28 (3),170https://doi.org/10.1176/appi.ap.28.3.170 
Roche AM, Sanson - Fisher RW, Cockburn J (1997) Training experiences immediately after medical school. Medical education 31 (1),9-16https://doi.org/10.1111/j.1365-2923.1997.tb00036.x

Shacklady J, Holmes E, Mason G, Davies I, Dornan T (2009) Maturity and medical students' ease of transition into the clinical environment. Medical teacher 31 (7),621-626https://doi.org/10.1080/01421590802203496

Smith J, Flowers P, Larkin M (2009) Interpretative Phoneomological Analysis, theory, method and research. London, SAGE Publications,

Teunissen PW, Westerman M (2011) Junior doctors caught in the clash, the transition from learning to working explored. Medical education 45 (10),968-970https://doi.org/10.1111/j.1365-2923.2011.04052.x

Thomson JS, Anderson K, Haesler E, Barnard A, Glasgow N (2014) The learner's perspective in GP teaching practices with multi-level learners, a qualitative study. BMC medical education 14 (1), 55https://doi.org/10.1186/1472-6920-14-55

Wilkinson TJ, Harris P (2002) The transition out of medical school-a qualitative study of descriptions of borderline trainee interns. Medical education 36 (5),466-471https://doi.org/10.1046/j.1365-2923.2002.01209.x 